\title{
Hepatotoxicity issues associated with antineoplastic drug carmustine: A brief review
}

\author{
Zorawar Singh* and Ankita Ahuja \\ P.G. Department of Zoology, Khalsa College Amritsar, Punjab, India
}

\begin{abstract}
Hepatotoxicity refers to the abnormal liver functions or various liver disorders which are influenced by some drugs or chemicals. A number of chemotherapeutic drugs are associated with some kind of toxicity including hepatotoxicity. Nowadays, cancer patients are mostly prone to hepatic dysfunction because the liver is the primary site to metabolize chemotherapeutic drugs. Carmustine or BCNU is an antineoplastic agent which is widely used as an anticancer drug against lymphomas, myeloma and brain tumors: glioblastoma and medullablastoma. The present review presents the hepatotoxic effects of carmustine by going through the present literature. Though, it is highly effective against malignant neoplasms but its toxicity to liver makes $\mathrm{BCNU}$ restricted to use. A dose ranging from 1500 to $2850 \mathrm{mg} / \mathrm{m}^{2}$ of $\mathrm{BCNU}$ proves fatal to the cancer patients causing hepatic necrosis. Exposure to BCNU for long term may lead to biliary cirrhosis and chloangiolysis.
\end{abstract}

\section{Introduction}

Carmustine or BCNU (1,3-Bis(2-chloroethyl)-1-nitrosourea) is a cell-cycle non-phase specific alkylating antineoplastic drug. $\mathrm{BCNU}$ as a single agent or in established combined therapy [1-5] with other agents has been used as a palliative therapy to treat certain types of brain tumors including glioblastoma [6], brain stem glioma, medullablastoma and metastatic brain tumors [7]. It is usually given by an infusion into a vein. Its usefulness has been limited by side effects which involves pericholangitis and intrahepatic cholestasis which in long term lead to chloangiolysis and biliary cirrhosis [8].

Carmustine is a nitrogen mustard $\beta$-chloro-nitrosourea compound which causes cross links in DNA and RNA. Chloroethylnitrosoureas are reactive compounds that are highly effective against malignant neoplasms in humans and animals [9]. It is an alkylating anticancer agent [10] and is orange yellow solid in appearance which may melt to an oily liquid. It possesses antiviral, antifungal and antibacterial properties but has not been used as anti-infectant till now. It is highly soluble in alcohol but poorly soluble in water. Figure 1 shows the chemical structure of carmustine.

Chemotherapy is known for killing cells that are rapidly dividing. Cancerous cells are remarked by their cell division as they lose mechanism known as contact inhibition which stops normal cells from infinite number of divisions. Usually drugs damage the nucleic acids of cancer cells including RNA or DNA so that their process of division may be halted. While carmustine alkylates and cross links DNA during all phases of cell cycles, resulting in disruption of DNA function; and stoppage of DNA replication, transcription and translation processes. It also binds and modifies glutathione<smiles>O=NN(CCCl)C(=O)NCCCl</smiles>

Figure 1. Chemical structure of Carmustine reductase. It is highly lipophilic and can cross the blood brain barrier readily. This drug also carbamoylates proteins, including DNA repair enzymes and may stop the cancer cell from its functioning. Though it is an effective drug against cancer cells, its higher dose may prove fatal. Its hepatotoxic effects have been presented below.

\section{Hepatotoxicity associated with BCNU}

The newer chemotherapy agents have revolutionized the treatment options for a wide variety of cancers [11]. Though, carmustine is highly effective drug used in chemotherapy, but we know merits and demerits goes simultaneously. There are some adverse effects associated with it while treatment of the patients including hepatotoxicity. Myelosuppression [12] and pulmonary toxicity [2] are the other ones. The toxicity of a drug is totally dependent upon dosage manner, so is with Carmustine. If the dosage given is lesser in amount, the hepatotoxicity may be mild and reversible, but if high doses are administered, it may prove fatal. Mostly hepatotoxicity from chemotherapeutic drugs is idiosyncratic [11]. So, carmustine is a drug with cholestatic potency both in experimental animals and in humans [13]. 26\% of the chemo patients were found to be suffering from hepatotoxic effects. The serum liver enzyme elevation raises the chances of acute liver injury including cholestatic hepatitis and acute veno-occlusive disease. Chemotherapy inducing hepatotoxicity may lead to increase in serum transaminases, alkaline phosphatases and bilirubin concentrates causing jaundice and portal system encephalopathy. Thus, BCNU possess high toxicity with slow recovery; thus, compromising the administration of drug in patients with progressive disease [14]. Table 1 presents the studies revealing the hepatotoxicity associated with carmustine or BCNU.

${ }^{\star}$ Correspondence to: Zorawar Singh, Department of Zoology, Khalsa College Amritsar, Punjab, India, Tel: +91-9417230075; E-mail: zorawarsinghs@ rediffmail.com

Key words: Carmustine, BCNU, toxicity, human, rats, cancer, chemotherapy

Received: December 06, 2018; Accepted: December 18, 2018; Published: December 24, 2018 
Table 1. Studies presenting the hepatotoxicity of carmustine or BCNU

\begin{tabular}{|c|c|c|c|c|c|c|}
\hline Sr.no & Author & Year & $\begin{array}{c}\text { Subject/ } \\
\text { model used }\end{array}$ & Dose administered & Observed hepatotoxic effects & Reference \\
\hline 1 & Jones et al. & 1989 & Human & $450 \mathrm{mg} / \mathrm{m}^{2}$ & Veno-occlusive liver disease & [15] \\
\hline 2 & Brandes et al. & 2004 & Human & $80 \mathrm{mg} / \mathrm{m}^{2}$ & Hepatic and pulmonary toxicity & [14] \\
\hline 3 & Cary et al. & 1980 & Human & $250 \mathrm{mg} / \mathrm{m}^{2}$ & Hepatocellular dysfunction & [16] \\
\hline 4 & Philips et al. & 1983 & Human & $\left(600-2850 \mathrm{mg} / \mathrm{m}^{2}\right)$ & Hepatic necrosis or fatal hepatotoxicity & {$[17]$} \\
\hline 5 & Girgin et al. & 2011 & Rat & $20 \mathrm{mg} / \mathrm{kg}$ in corn oil & Lipoperoxidation & [8] \\
\hline 6 & Laquerrie et al. & 1991 & Rat & More than $50 \mathrm{mg} / \mathrm{kg}$ & Hepatocyte cell cycle alteration & [9] \\
\hline 7 & Hoyt and Larson & 1989 & Rat & $20 \mathrm{mg} / \mathrm{kg}$ & Cholestasis & {$[18]$} \\
\hline 8 & Krell et al. & 1991 & Rat & & Hepatotoxic lesions & [13] \\
\hline 9 & Nakae et al. & 1988 & Rat & & Increased hepatotoxicity & {$[19]$} \\
\hline 10 & Stolzenbach and Larson & 1990 & Rat & - & Changes in hepatic cytochrome $\mathrm{P}-450$ & {$[20]$} \\
\hline
\end{tabular}

No doubt, chemotherapy is like a bliss to the cancer patients but the compounds or drugs that are used in chemotherapy are proved toxic as well. Here, in this paper, several studies have been presented with the different concentrations of carmustine used on rats as well as humans resulting in hepatotoxic effects like lipoperoxidation, fluctuations in level of bilirubin, cholestasis, veno-occlusive liver diseases and hepatocytes cell-cycle alterations. In several types of cancers like leukemia or glioblastoma, carmustine either singly or with some other agents is given to patients which may resulting to hepatic dysfunction. In few of the patients suffering from glioblastoma, when treated with $80 \mathrm{mg} / \mathrm{m}^{2} \mathrm{BCNU}$, severe hepatotoxicity was observed [14]. Similarly, in another case, patient with bronchogenic carcinoma was given Amphotericin B for respective 3-4 days and on $4^{\text {th }}$ day BCNU $\left(250 \mathrm{mg} / \mathrm{m}^{2}\right)$ was also added. It was observed that in first three days, less than $50 \%$ tumour area was reduced and few of patients had small or large cell undifferentiated carcinoma. But when BCNU was added, one of patient died because of hepatic dysfunction. Apart from its hepatotoxic effect, it was also found that Amphotericin B may enhance the antitumor effects of nitrosoureas or other known antitumor agents [16].

Similarly, there are some drugs which enhance the hepatotoxic properties of BCNU like BCNU + Acetaminophen. In a study, when male rats were treated with acetaminophen alone, no liver necrosis was found. But when it was given with 3-methylcholanthrene, hepatotoxic effect of acetaminophen was found to be enhanced. Some rats were pre-treated with BCNU for inhibition of glutathione reductase; which potentiated the hepatotoxicity of acetaminophen induced by 3-methylcholanthrene [19]. Qualitative and quantitative changes in the cytochrome P-450 are also the major effects caused by BCNU. A remarkable decrease in the content of cytochrome P-450 has been noted which caused changes in the bile acids and various proteins [20]. BCNU $(20 \mathrm{mg} / \mathrm{kg})$ may result in intra-hepatic cholestasis in rats [18]. Cholestasis is characterized by a selective reduction of the bile salt independent fraction of bile flow [18]. The plasma amounts of $\mathrm{K}^{+}$increase and $\mathrm{Na}^{+}$decrease as an effect of cholestasis. If cholestasis prolongs, it may lead to biliary cirrhosis and cholangiolysis. The nitrosoureas carmustine are known to cause alterations in cell cycle of hepatocytes [9]. The permeability of bile tract also gets increased with BCNU in rat's body. The paracellular sucrose tends to enter bile tract through the process of diffusion or convection, resulting in hepatic lesions [13]. Trimetazidine (TMZ) is an antianginal compound and its effects on liver were checked in rats in combination with BCNU. Results revealed a significant decrease in the GSH level in BCNU+TMZ treated rats. TMZ administration tends to increase GSH in BCNU+TMZ treated rats as compared to rats treated with $\mathrm{BCNU}$ alone. Thus, TMZ proved to be a protective agent for the liver functioning [17]. The hepatotoxic potential of BCNU gets more pronounced when it was given in combined dosage with carboplatin and cyclophosphamide [15]. The difference in the dosage range of BCNU causes different diseases like dosage ranging amidst 1500 to $2850 \mathrm{mg} / \mathrm{m}^{2}$ leads to fatal hepatic necrosis [17].

\section{Conclusion}

Carmustine or BCNU is an antineoplastic agent which is extensively used as an anticancer drug against lymphomas, myeloma and brain tumors: glioblastoma and medullablastoma. The present review presents the hepatotoxic effects of carmustine by going through the available studies. Various hepatotoxic effects associated with carmustine may include lipoperoxidation, fluctuations in level of bilirubin, cholestasis, veno-occlusive liver diseases and hepatocyte cell-cycle alterations. A dose ranging from 1500 to $2850 \mathrm{mg} / \mathrm{m}^{2}$ of BCNU was found to be causing hepatic necrosis. Exposure to $\mathrm{BCNU}$ for long term may lead to biliary cirrhosis and chloangiolysis. Conclusively, BCNU should be administered only under a proper dose regime.

\section{Acknowledgements}

Authors thank head and staff of Department of Zoology, Khalsa College Amritsar for their constant support throughout the work.

\section{Funding}

There is no funding source for the present study

\section{Availability of data and materials}

Not applicable

\section{Competing interest}

None declared

\section{Ethics approval and consent to participate}

Not applicable

\section{Financial support and sponsorship}

\section{None}

\section{References}

1. Akiyama Y, Kimura Y, Enatsu R, Mikami T, Wanibuchi M, et al. (2018) Advantages and Disadvantages of Combined Chemotherapy with Carmustine Wafer and Bevacizumab in Patients with Newly Diagnosed Glioblastoma: A Single-Institutional Experience. World Neurosurg 113: e508-e514.

2. Bock HC, Puchner MJ, Lohmann F, Schutze M, Koll S, et al. (2010) First-line treatment of malignant glioma with carmustine implants followed by concomitant radiochemotherapy: a multicenter experience. Neurosurg Rev 33: 441-449. 
3. Brandes AA, Tosoni A, Basso U, Reni M, Valduga F, et al. (2004) Second-line chemotherapy with irinotecan plus carmustine in glioblastoma recurrent or progressive after first-line temozolomide chemotherapy: a phase II study of the Gruppo Italiano Cooperativo di Neuro-Oncologia (GICNO). J Clin Oncol 22: 4779-4786.

4. Cecchin D, Schiorlin I, Della PA, Lombardi G, Zucchetta P, et al. (2014) Assessing response using $99 \mathrm{mTc}-\mathrm{MIBI}$ early after interstitial chemotherapy with carmustineloaded polymers in glioblastoma multiforme: preliminary results. Biomed Res Int 2014: 684383 .

5. Cheng YC, Rondón G, Yang Y, Smith TL, Gajewski JL, et al. (2004) The use of highdose cyclophosphamide, carmustine, and thiotepa plus autologous hematopoietic stem cell transplantation as consolidation therapy for high-risk primary breast cancer after primary surgery or neoadjuvant chemotherapy. Biol Blood Marrow Transplant 10: 794804. [Crossref]

6. Fukai J, Nishibayashi H, Uematsu Y, Kanemura Y, Fujita K, et al. (2016) Rapid regression of glioblastoma following carmustine wafer implantation: A case report. Mol Clin Oncol 5: 153-157.

7. Ene CI, Nerva JD, Morton RP, Barkley AS, Barber JK, et al. (2016) Safety and efficacy of carmustine (BCNU) wafers for metastatic brain tumors. Surg Neurol Int 7: S295299. [Crossref]

8. Girgin F, Tüzün S, Demir A, Kuralay F, Ozutemiz O, et al. (1999) Cytoprotective effects of trimetazidine in carmustine cholestasis. Exp Toxicol Pathol 51: 326-329. [Crossref]

9. Laquerriere A, Raguenez-Viotte G, Paraire M, Bizzari JP, Paresy M, et al. (1991) Nitrosoureas lomustine, carmustine and fotemustine induced hepatotoxic perturbations in rats: biochemical, morphological and flow cytometry studies. Eur J Cancer 27: 630638. [Crossref]

10. Arai H, Yamauchi T, Uzui K, Ueda T (2015) Leukemia cells are sensitized to temozolomide, carmustine and melphalan by the inhibition of $\mathrm{O}(6)$-methylguanineDNA methyltransferase. Oncol Lett 10: 845-849.

11. Thatishetty AV, Agresti N, O'Brien CB (2013) Chemotherapy-Induced Hepatotoxicity. Clinics in Liver Disease 17: 671-686.
12. Buckner JC, Ballman KV, Michalak JC, Burton GV, Cascino TL, et al. (2006) Phase III trial of carmustine and cisplatin compared with carmustine alone and standard radiation therapy or accelerated radiation therapy in patients with glioblastoma multiforme: North Central Cancer Treatment Group 93-72-52 and Southwest Oncology Group 9503 Trials. J Clin Oncol 24: 3871-3879.

13. Krell H, Fromm H, Larson RE (1991) Increased paracellular permeability in intrahepatic cholestasis induced by carmustine (BCNU) in rats. Gastroenterology 101: 180-188. [Crossref]

14. Brandes AA, Tosoni A, Amistà P, Nicolardi L, Grosso D, et al. (2004) How effective is BCNU in recurrent glioblastoma in the modern era? A phase II trial. Neurology 63 : 1281-1284. [Crossref]

15. Jones RB, Shpall EJ, Ross M, Coniglio D, Affronti ML, et al. (1990) High-dose carboplatin, cyclophosphamide, and BCNU with autologous bone marrow support: excessive hepatic toxicity. Cancer Chemother Pharmacol 26: 155-156. [Crossref]

16. Cary A, Presant MD, Stephen Hillinger MD (1980) Phase II study of 1,3-Bis(2chloroethyl)-1-nitrosourea (BCNU, NSC \#409962) with amphotericin B in bronchogenic carcinoma. Cancer 45: 6-10.

17. Phillips GL, Fay JW, Herzig GP, Herzig RH, Weiner RS, et al. (1983) Intensive 1,3-bis(2-chloroethyl)-1-nitrosourea (BCNU), NSC \#4366650 and cryopreserved autologous marrow transplantation for refractory cancer. A phase I-II study. Cancer 52: $1792-1802$.

18. Hoyt D, Larson RE (2013) Cholestatic effect of carmustine in rats. Curr Med Chem 20: $772-781$.

19. Nakae D, Oakes JW, Farber JL (1988) Potentiation in the intact rat of the hepatotoxicity of acetaminophen by 1,3-bis(2-chloroethyl)-1-nitrosourea. Arch Biochem Biophys 267: 651-659. [Crossref]

20. Stolzenbach JC, Larson RE (1990) BCNU-induced quantitative and qualitative changes in hepatic cytochrome P-450 can be correlated with cholestasis. Cancer Chemother Pharmacol 25: 227-235.

Copyright: (C2018 Singh Z. This is an open-access article distributed under the terms of the Creative Commons Attribution License, which permits unrestricted use, distribution, and reproduction in any medium, provided the original author and source are credited. 